\title{
Validation of Consensus Quantitative Trait Loci Associated with Resistance to Multiple Foliar Pathogens of Maize
}

\author{
Godfrey Asea, Bindiganavile S. Vivek, George Bigirwa, Patrick E. Lipps, and Richard C. Pratt
}

First and fifth authors: Department of Horticulture and Crop Science, The Ohio State University, Ohio Agricultural Research and Development Center (OSU/OARDC), Wooster, OH 44691; second author, CIMMYT, P.O. Box MP163, Mt. Pleasant, Harare, Zimbabwe; third author, National Crops Resources Research Institute, Namulonge, P.O. Box 7084, Kampala, Uganda; fourth author, Department of Plant Pathology, OSU/OARDC, Wooster.

Accepted for publication 31 December 2008.

\begin{abstract}
Asea, G., Vivek, B. S., Bigirwa, G., Lipps, P. E., and Pratt, R. C. 2009. Validation of consensus quantitative trait loci associated with resistance to multiple foliar pathogens of maize. Phytopathology 99:540-547.

Maize production in sub-Saharan Africa incurs serious losses to epiphytotics of foliar diseases. Quantitative trait loci conditioning partial resistance (rQTL) to infection by causal agents of gray leaf spot (GLS), northern corn leaf blight (NCLB), and maize streak have been reported. Our objectives were to identify simple-sequence repeat (SSR) molecular markers linked to consensus rQTL and one recently identified rQTL associated with GLS, and to determine their suitability as tools for selection of improved host resistance. We conducted evaluations of disease severity phenotypes in separate field nurseries, each containing $410 \mathrm{~F}_{2: 3}$

maize streak resistant) and VP31 (a GLS-resistant breeding line) that possess complimentary rQTL. $\mathrm{F}_{2: 3}$ families were selected for resistance based on genotypic (SSR marker), phenotypic, or combined data and the selected $\mathrm{F}_{3: 4}$ families were reevaluated. Phenotypic values associated with SSR markers for consensus rQTL in bins 4.08 for GLS, 5.04 for NCLB, and 1.04 for maize streak significantly reduced disease severity in both generations based on single-factor analysis of variance and marker-interval analysis. These results were consistent with the presence of homozygous resistant parent alleles, except in bin 8.06, where markers were contributed by the NCLB-susceptible parent. Only one marker associated with resistance could be confirmed in bins 2.09 (GLS) and 3.06 (NCLB), illustrating the need for more robust rQTL discovery, fine-mapping, and validation prior to undertaking marker-based selection.
\end{abstract} families derived from a cross between maize inbred CML202 (NCLB and
Maize (Zea mays L.) productivity suffers in many agroecosystems worldwide due to the devastating effects of foliar diseases $(24,28)$. Gray leaf spot (GLS), caused by Cercospora zeae-maydis Tehon \& E. Y. Daniels; northern corn leaf blight (NCLB), incited by Exserohilum turcicum (Pass.) K. J. Leonard \& Suggs (teleomorph = Setosphaeria turcica (Luttr.) K. J. Leonard \& Suggs; syn. = Helminthosporium turcicum Pass.); and maize streak, caused by Maize streak mastrevirus (MSV) infection, are three of the most destructive diseases $(1,5,39)$ in sub-Saharan Africa. Losses due to each of the diseases may exceed $30 \%$ in endemic areas $(6,30,39)$. Unfortunately, these diseases may also occur simultaneously, resulting in even more severe crop losses.

In maize, there already exists information concerning the genetic basis of host resistance and pathogen virulence for several pathosystems, including NCLB (41). Host resistance is generally considered the most practical, cost-effective, and environmentally acceptable means for managing maize diseases $(3,28)$. Quantitative (partial) resistance is now emphasized in maize breeding because high levels of resistance can be achieved $(21,28)$. It is also assumed that partial resistance will be more durable than qualitative resistance because it should remain effective against all races of a pathogen and minimize evolution of new races $(20,25)$.

A number of quantitative trait loci conditioning partial resistance (rQTL) conferring resistance to GLS $(7,9,15,19,33)$, NCLB $(13,14,42,44)$, and maize streak $(18,26,27,43)$ have been reported. The majority of these studies used relatively small population

Corresponding author: R. C. Pratt; E-mail address: pratt.3@osu.edu

doi:10.1094/PHYTO-99-5-0540

(c) 2009 The American Phytopathological Society sizes, resulting in low power for QTL detection. Imprecise estimates of QTL location are also common due to low power of resolution. Some QTL in these studies were consistent across experiments (mapped intervals overlapped) and we deemed these regions "consensus" rQTL (Table 1).

Marker-based or marker-assisted selection (MAS) using validated target rQTL could become an important strategy for improving host resistance to multiple foliar pathogens. Breeders must first document the reproducibility of candidate markerintervals (e.g., consensus rQTL) in their unique populations and target environments of interest before considering them targets for selection. The majority of the studies cited above also used restriction fragment length polymorphism (RFLP) markers which are not readily amenable for practical breeding, especially in resource-limited developing countries. The substitution of more cost-effective polymerase chain reaction (PCR)-based molecular markers for RFLP markers would be desirable. Pyramiding multiple rQTL would also broaden the spectrum of host resistance and, possibly, the durability of that resistance.

The objectives of this study were to (i) identify simple-sequence repeat (SSR) markers polymorphic between resistant and susceptible genotypes linked to consensus rQTL conferring resistance to infection by $C$. zeae-maydis (bin 4.08), E. turcicum (bins 3.06, 5.04 and 8.06), MSV (bin 1.04), and one newly reported QTL associated with GLS resistance in bin 2.09 and (ii) validate the candidate rQTL presented above across $F_{2: 3}$ and $F_{3: 4}$ families derived from tropical and temperate maize.

\section{MATERIALS AND METHODS}

Plant materials. Resistance to infection by MSV and $E$. turcicum has been identified in CIMMYT inbred line CML202 
which is adapted to the midaltitude tropics $(42,43)$. VP31 is a partially inbred breeding line $\left(\mathrm{F}_{3: 4}\right)$ derived from the cross between a $C$. zeae-maydis-resistant South African maize inbred line (VO613Y) and a susceptible Corn Belt maize inbred line (Pa405). VP31 displays resistance to $C$. zeae-maydis infection and matures considerably earlier than its parent VO613Y (15). A hybrid between CML202 and VP31 was produced using controlled pollination of individual plants, and the resulting hybrid was self-pollinated to produce $F_{2}$ seed. $F_{2: 3}$ families were developed by self-pollinating $410 \mathrm{~F}_{2}$ plants. Self-pollination of single plants within each of the selected $\mathrm{F}_{2: 3}$ families provided $\mathrm{F}_{3: 4}$ families wherein all individuals were identical by descent from an individual $\mathrm{F}_{2}$ plant. The following numbers of families were advanced to the $\mathrm{F}_{3: 4}: 38$ for GLS, 37 for maize streak, and 38 for NCLB. These numbers corresponded to selection intensity of $\approx 10 \%$ (following discard of extremely late-maturing $\mathrm{F}_{2: 3}$ families) and at truncation points of 1.0 standard deviation unit from the mean for GLS and NCLB and 2.0 standard deviation units for maize streak. All resistant families and a set of nonselected families were entered into each disease nursery. Production of the $\mathrm{F}_{3: 4}$ families in this manner enabled us to further examine rQTL after another cycle of inbreeding and established the basis for future research on heritability and gain through selection.

GLS study. Field trial. The $\mathrm{F}_{2: 3}$ and $\mathrm{F}_{3: 4}$ families were evaluated for partial resistance in field trials conducted at the Ohio Agricultural Research and Development Center (OARDC) Fry Farm near Wooster, OH in 2003 and 2004, respectively. The site contained a large amount of maize debris ( $>50 \%$ soil surface coverage) from previous no-till plots. Chlorpyrofos insecticide (O,O-diethyl $O$-3,5,6-trichloro-2-pyridyl phosphorothioate) was applied in the furrow at planting. Weeds were controlled by application of 1,3,5-Triazine-2,4-diamine (Bullet; Monsanto Company) and hand weeding as necessary. Because of limitations in available land, $\mathrm{F}_{2: 3}$ families were evaluated using an augmented experimental design constructed using a randomized complete block design (RCB) as described by Federer et al. (12). The $410 \mathrm{~F}_{2: 3}$ families were distributed randomly in 10 blocks, each containing 49 entries (resistant and susceptible local checks, the parents, and 41 $\mathrm{F}_{2: 3}$ families). Inbred lines Pa405 and $\mathrm{H} 100$ were planted as susceptible checks while inbred line VO613Y served as resistant check. Check treatments and parental inbred lines were replicated 20 times ( 2 replicates per block) to allow for calculation of an error term and to account for any spatial variation in the field. $F_{3: 4}$ families were planted in a simple RCB design with two replicates. Each plot was a single row into which 20 seeds were sown at a distance of $30 \mathrm{~cm}$ between hills and $75 \mathrm{~cm}$ between rows. To increase the spread of C. zeae-maydis, inbred line B73 (susceptible) was planted in guard rows. Guard rows separated each plot from the adjacent plot and every fifth range was planted entirely to B73.

Inoculation. Conidia of C. zeae-maydis were isolated from senesced maize leaves collected the previous season from diseased fields. Isolates from Apple Creek, OH were used in 2003 while isolates from fields near Wooster, OH were used in 2004. Leaves were air dried and stored in polythene bags at room temperature until use. Aseptic hyphal cultures were maintained as

TABLE 1. Consensus quantitative trait loci conditioning partial resistance (rQTL) of field maize associated with reduced severity of gray leaf spot (GLS), maize streak (MSV), and northern corn leaf blight (NCLB) in CML202 and VO613Y ${ }^{\mathrm{w}}$

\begin{tabular}{|c|c|c|c|c|}
\hline Reference $^{\mathrm{x}}$ & Resistance source & Marker interval & $\operatorname{Bin}^{y}$ & Coordinates \\
\hline \multicolumn{5}{|l|}{ GLS } \\
\hline Bubeck et al. 1993 (7) & ADENT & umc19-bnl7.65 & $4.07-4.08$ & 414.2-464.8 \\
\hline Gordon et al. 2004 (15) & VO613Y & PIC21-umc127(c) & 4.08 & PIC21-9cM-443.9 \\
\hline Saghai-Maroof et al. 1996 (33) & B73 & npi444-umc15(a) & 4.08 & $524.1-525.8$ \\
\hline Overall region & $\ldots$ & $\ldots$ & $4.07-4.08$ & $414.2-525.8$ \\
\hline Consensus region & $\ldots$ & $\ldots$ & 4.08 & 9-443.9 \\
\hline \multicolumn{5}{|l|}{ NCLB } \\
\hline Schechert et al. 1999 (35) & CML202 & bnl8.01-umc389b & 3.06 & $423.4-138.0^{\mathrm{z}}$ \\
\hline Freymark et al. 1993 (14) & Mo17 & umc60-bnl15.20 & $3.06-3.07$ & $452.7-535.8$ \\
\hline Welz et al. 1999 (42) & CML202 & umc $361-$ bnl15.20 & 3.06-3.07 & $491.4-535.8$ \\
\hline Freymark et al. 1994 (13) & Mo17 & итс39-итс16 & $3.06-3.07$ & $508.0-582.9$ \\
\hline Welz et al. 1999 (44) & D145 & umc $3 b-u m c 17 a$ & $3.06-3.08$ & $529.4-585.5$ \\
\hline Overall region & $\ldots$ & $\ldots$ & $3.06-3.08$ & $138.0-585.5$ \\
\hline Consensus region & $\ldots$ & $\ldots$ & $3.06-3.07$ & $529.4-535.8$ \\
\hline Freymark et al. 1994 (13) & Mo17 & umc90--bnl7.71 & $5.02-5.04$ & $147.5-318.9$ \\
\hline Freymark et al. 1993 (14) & Mo17 & bnl10.06-bnl7.71 & $5.03-5.04$ & 294.9-318.9 \\
\hline Freymark et al. 1993 (14) & Mo17 & umc1-bnl5.40 & $5.03-5.06$ & $280.8-461.5$ \\
\hline Welz et al. 1999 (44) & D145 & $\operatorname{csu} 36 a(b)-b n l 7.71$ & $5.03-5.04$ & $301.6-318.9$ \\
\hline Welz et al. 1999 (42) & CML202 & umc001-bnl5.40 & 5.04-5.06 & $280.8-461.5$ \\
\hline Overall region & $\ldots$ & $\ldots$ & $5.02-5.06$ & $147.5-461.5$ \\
\hline Consensus region & $\ldots$ & $\ldots$ & $5.03-5.04$ & $280.8-461.5$ \\
\hline Freymark et al. 1994 (13) & Mo17 & bnl9.08-bnl7.08 & $8.03-8.04$ & $278.7-298.6$ \\
\hline Freymark et al. 1993 (14) & Mo17 & bnl7.08-bnl8.26 & $8.04-8.05$ & $298.6-368.7$ \\
\hline Welz et al. 1999 (42) & CML202 & bnl12.30(a)-umc30(a) & 8.05-8.06 & $385.5-408.5$ \\
\hline Freymark et al. 1993 (14) & Mo17 & uтс323-umc30(a) & 8.06 & $388.8-408.5$ \\
\hline Welz et al. 1999 (44) & D145 & umc17b-npi268a & $8.06-8.07$ & $388.9-459.2$ \\
\hline Overall region & $\ldots$ & $\ldots$ & $8.03-8.07$ & $278.7-459.2$ \\
\hline Consensus region & $\ldots$ & $\ldots$ & $8.04-8.06$ & $298.6-408.5$ \\
\hline \multicolumn{5}{|l|}{ MSV } \\
\hline Kyetere et al. 1999 (18) & Tzi4 & bnl12.06a-npi262 & $1.03-1.04$ & $293.0-383.7$ \\
\hline Pernet et al. 1999 (27) & D211 & $\operatorname{asg} 30(b)-c s u 92$ & $1.04-1.06$ & $340.7-508.2$ \\
\hline Pernet et al. 1999 (27) & CIRAD390 & asg30(b)-umc177 & $1.04-1.06$ & $340.7-529.3$ \\
\hline Welz et al. 1998 (43) & CML202 & umc302-umc167(a) & 1.05 & $405.0-454.1$ \\
\hline Overall region & $\ldots$ & $\ldots$ & $1.03-1.06$ & $293.0-29.3$ \\
\hline Consensus region & $\ldots$ & $\ldots$ & $1.04-1.06$ & $340.7-08.2$ \\
\hline
\end{tabular}

${ }^{w}$ Map coordinates were located using IBM2 2005 neighbors as reference map.

${ }^{x}$ Overall region $=$ total region spanned by rQTL discovered in all reports and consensus region $=$ overlapping rQTL region within overall region.

y Bin numbers in bold identify regions associated with parents used in this study.

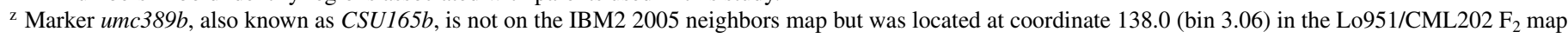
(44). 
described by Asea et al. (2). Plugs from 10- to 25-day-old sporulating colonies were used to colonize sorghum (Sorghum bicolor) kernels in half-full 1-liter autoclavable plastic containers. Infested kernels were air dried and thereafter kept dry at $10^{\circ} \mathrm{C}$ until used for inoculation. In 2003, $\mathrm{F}_{2: 3}$ families and inbred checks were inoculated twice at 1-week intervals, starting at the V6 growth stage (31), by placing $\approx 10$ to 20 infested sorghum kernels into the leaf whorls of all plants. In 2004, plots were inoculated when the majority of plants were at the V8 growth stage (31). After each inoculation, low-volume overhead irrigation sprinklers were used to apply water once daily at dusk for $\approx 30$ min to extend the period of leaf wetness. Supplemental irrigation was also performed in this manner when periodic environmental conditions were not considered conducive to disease progress.

Disease severity assessment. Disease assessments for GLS were made on a whole-plot basis commencing 46 days after the first inoculation (DAI). The first disease score was made at the R1 growth stage (31), the time when $\approx 50 \%$ of plants displayed visible silk exertion. Silk exertion data was collected in the 2003 GLS plots in Ohio and 2003 MSV plots in Zimbabwe. Standard assessment diagrams developed by Ward et al. (38) were used as a guide in estimating disease severity. The scale assigns a percentage leaf area affected (PLAA) score based on visual estimates of the percentage of surface area of leaves covered by lesions on single plants. Instead of individual plant assessments, visual estimates were made on whole plots because each plot constituted a family and symptom reactions within families were similar. A second assessment was made at the approximate mid-epiphytotic stage (53 DAI) and a final rating was made 62 DAI. The three scores were used to calculate standardized area under disease progress curves (SAUDPC) $=\Sigma\left[\left(x_{i}+x_{i+1}\right) / 2\right]\left(t_{i+1}-t_{i}\right)$ illustrated by Campbell and Madden (8). Standardization was performed using the time span necessary for disease assessments (in days), and where $x_{i}$ is the disease rating on date $i$ and $t_{i}$ is the time (in calendar days) on which $x_{i}$ was recorded.

NCLB study. Experiments with $\mathrm{F}_{2: 3}$ families were planted in a simple RCB design with two replicates at the National Crops Resources Research Institute, Namulonge, Uganda in 2003. F families were planted at the OARDC Schaffter Farm near Wooster, $\mathrm{OH}$ in 2004. In both seasons, inbred line H100 was planted as a susceptible check while the parental inbred line CML202 served as the resistant check. Plots in Namulonge were established in a field maintained in maize-soybean (Glycine max) rotation. This site is located in the tropical midaltitude Lake Victoria Crescent agroecological zone, with a mean temperature of $20^{\circ} \mathrm{C}$ (46). The zone is characterized by a bimodal rainfall regime with a mean annual precipitation of $1,200 \mathrm{~mm}$. Two seeds were planted per hill (17 hills per plot) at a distance of $30 \mathrm{~cm}$ between hills and $75 \mathrm{~cm}$ between rows. Two weeks after planting, hills were thinned to one plant to maintain a plant density of $\approx 54,000$ plants ha $^{-1}$. The Wooster site $\left(\mathrm{F}_{3: 4}\right.$ trial $)$ was plowed following alfalfa (Medicago sativa) and employed the same RCB design with two replicates. Plot architecture and management treatments were the same as those employed in the GLS trials described above.

Inoculation. E. turcicum inoculum was produced from isolates obtained from infected maize leaves from Namulonge, Uganda and Licking County, OH. Isolates from Namulonge were kept separately and used in Uganda (2003) while isolates from Licking County were used in the 2004 trials planted in Ohio. Aseptic cultures were produced from sporulating conidia and maintained in petri plates containing lactose-casein hydrolysate agar (37). Colonized media sections from the culture were placed onto sorghum kernels as described above. Cultures were subsequently handled according to the protocol described by Hakiza et al. (16). Before inoculation, race-specific virulence of the isolates obtained from Ohio was established by inoculating known differential inbred lines of maize (H4460, H4460Htl, H4460Ht3,
A619, A619Ht1, and A619Ht2) grown in the greenhouse at the OARDC. Based on the specific reactions of these differentials, isolates were confirmed to be a mixture of races 0 and 1 in approximately equal proportions for trials conducted in Ohio. Plots were inoculated using the same method as described for $C$. zeae-maydis starting at the V6 growth stage. Trials conducted in Uganda were inoculated using a method similar to that described above. Earlier pathogen race monitoring in Uganda indicated the presence of only race $0(1,4)$, although the racial profile of the pathogen population during the 2003 evaluations was unknown.

Disease severity assessments. Visual ratings were made on a whole-plot basis in the same manner as GLS assessments described above, with the exception that they commenced 43 DAI and were performed again 50 and 60 DAI using the protocol described by Hakiza et al. (16).

MSV study. MSV experiments with both $\mathrm{F}_{2: 3}$ and $\mathrm{F}_{3: 4}$ families were conducted at the Centro Internacional de Mejoramiento de Maiz y Trigo (Center for Maize and Wheat Improvement; CIMMYT) Experimental Station at Mt. Pleasant in Zimbabwe in 2003 and 2004. Experimental design and plots at Zimbabwe were established similar to those in Uganda but were thinned only after maize streak symptoms appeared. Parental inbred line CML202 served as resistant check while temperate inbred lines B73, Pa405, and H100 were used as susceptible checks. Standard management practices for maize production in the subhumid natural region II of Zimbabwe were employed (22).

Leafhoppers (Cicadulina mbila, Naude) were reared on millet (Pennisetum americanum) seedlings as described by Mawere et al. (22). Inoculations were performed when the majority of plants were at the V3 stage using three viruliferous, anaesthetized leafhoppers placed into the leaf whorl of each plant. Leafhoppers were allowed to feed on the maize seedlings for 1 week. The plots were then sprayed with a systemic dimethoate insecticide (2-dimethoxyphosphinothioylthio- $N$-methylacetamide) to prevent damage from other pests.

Maize streak symptom severity scores were rated 52 DAI when a range of characteristic foliar symptoms were observable. Disease severity was rated on a commonly used standard scale of 1 to 5 with 0.5 increments, where 1 was the most resistant; showing no symptoms of infection, and 5 was severely affected (43). Disease ratings of the $\mathrm{F}_{3: 4}$ families were performed using the same procedure as for the $\mathrm{F}_{2: 3}$.

Genotypic analysis. Chromosomal regions where NCLB and MSV consensus rQTL and GLS rQTL have been mapped in the same regions reported for resistant inbred lines CML202 and VO613Y (parent of VP31) are presented in Table 1. We identified the regions in common across studies (consensus regions) and attempted to identify SSR markers linked to the rQTL for GLS in consensus region (chromosomal bin) 4.08 (15); NCLB rQTL in bins 3.06, 5.04, and 8.05-8.06 (41); a consensus MSV rQTL in bin 1.04-1.05 $(18,26,27,43)$; and a newly reported rQTL associated with GLS in bin 2.09 (15). Oligonucleotide primer sequences were obtained from the Maize Genetics and Genomics database (available online) and used to detect polymorphisms between the parents. It was not always possible to identify polymorphic markers within the consensus regions; therefore, the closest polymorphic markers that could be obtained were used. Primer sequences were purchased from Research Genetics (Huntsville, AL). The rate of polymorphism between the parents was $19 \%$. Pairs of informative markers in the consensus rQTL region (or as close as possible) where used for screening the population to detect if there was an association between the new SSR markers and resistance.

For genotypic analysis, leaf tissue from 10 field-grown $F_{2: 3}$ plants per family and five $\mathrm{F}_{3: 4}$ plants per family was sampled and pooled. Out of 20 plants in $F_{2: 3}$ family rows, 10 plants were sampled to capture genetic variation within the families. The sample was reduced to half in the $\mathrm{F}_{3: 4}$ because heterozygosity is 
expected to be reduced by half in the subsequent generation. Genomic DNA was extracted from 4-week-old seedlings using a cetyltrimethylammonium bromide procedure (17). PCR methods were performed as described by Davis et al. (11). Electrophoresis was conducted on agarose gels (Ameresco, Solon, $\mathrm{OH}$ ) with concentrations of 3.5 to $4.5 \%$.

Statistical analyses. In both generations, marker data were scored as homozygous for one parental allele, homozygous for the other parental allele, and heterozygous. The $\chi^{2}$ analyses were carried out for each marker in the $\mathrm{F}_{2: 3}$ to test the distribution of observed allele frequencies against those expected for the segregation model $(1: 2: 1)$. Independence of residuals and normality tests for phenotypic data were evaluated by the RyanJoiner test (similar to Shapiro-Wilks test) and equality of variance, as well as summary statistics, were calculated at $95 \%$ Bonferroni confidence intervals using the MINITAB statistical

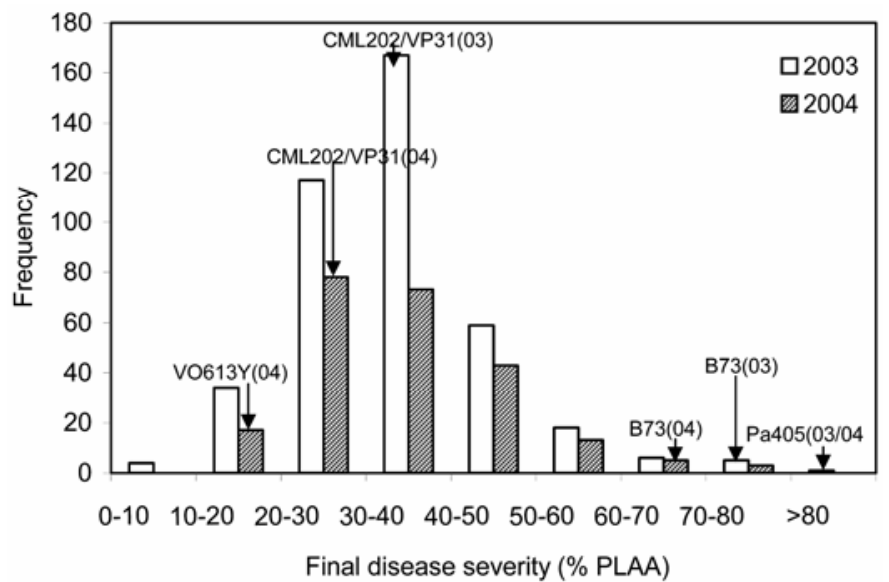

Fig. 1. Frequency distribution of final disease severity (percentage leaf area affected [PLAA]) ratings of $\mathrm{F}_{2: 3}$ and $\mathrm{F}_{3: 4}$ families from CML202/VP31 cross evaluated for gray leaf spot near Wooster, OH during 2003 and 2004, respectively. package. Residuals of disease ratings for NCLB were not normally distributed and consequently data were transformed by a $\log 10$ (datum +1) transformation to normalize variance as described by Gordon et al. (15).

Associations between individual marker loci and disease severity were tested with single-factor analysis of variance (ANOVA) using the PROC GLM procedure (34), with a threshold significance level of $P=0.05$. For tests of marker-trait association within the population, the statistical model used was the same as that described by Coaker et al. (10)

Total phenotypic variation explained by the marker loci was calculated by estimating variance components by restricted maximum likelihood (REML) using the VARCOMP procedure of SAS (34). Because the experiments for $\mathrm{F}_{2: 3} \mathrm{MSV}$ and NCLB and all $\mathrm{F}_{2: 4}$ disease evaluations were replicated, the phenotypic variation explained by the effect of QTL were expressed as the variation due to the marker divided by the total variation $\left(\mathrm{V}_{\mathrm{m}} / \mathrm{V}_{\mathrm{p}}\right)$. Interval analysis was calculated using scores of both SSR markers in or adjacent to the consensus QTL region. If both markers were homozygous for one parent (CC CC), then it was scored as 1 ; if both were homozygous for the other parent ( VV VV), then it was scored as 2, if heterozygous (VC) it was scored as 3; and, if both marker scores were different (recombinants), then the QTL region (CV VV CC) was scored as 4. Associations between both markers coded as a locus and disease severity were tested with ANOVA as described above.

\section{RESULTS}

GLS. Weather conditions and levels of inoculum, including that from infested debris from the previous crop, were favorable for early GLS development during both seasons. Disease severity values were continuously distributed with significant $(P<0.01)$ transgressive segregation occurring during both trials (Fig. 1). The most resistant families had $<10 \%$ final PLAA and several susceptible families were $>50 \%$ affected (Table 2). Susceptible checks Pa405 and B73 were severely affected ( $>70 \%$ PLAA at the final rating; 63 DAI). Disease severity of both parental checks was

TABLE 2. Means of disease severity (standardized area under disease progress curves [SAUDPC] and 1 to 5 scale) and days to mid-silk values of the parent lines, check inbred lines, and $\mathrm{F}_{2: 3}$ families inoculated independently with Cercospora zeae-maydis, Exserohilum turcicum, or Maize streak virus (MSV) among $\mathrm{F}_{2 \cdot 3}$ and selected $\mathrm{F}_{3: 4}$ families evaluated at Wooster, OH; Namulonge, Uganda; and CIMMYT Zimbabwe, respectively, during 2003 and $2004^{\mathrm{y}}$

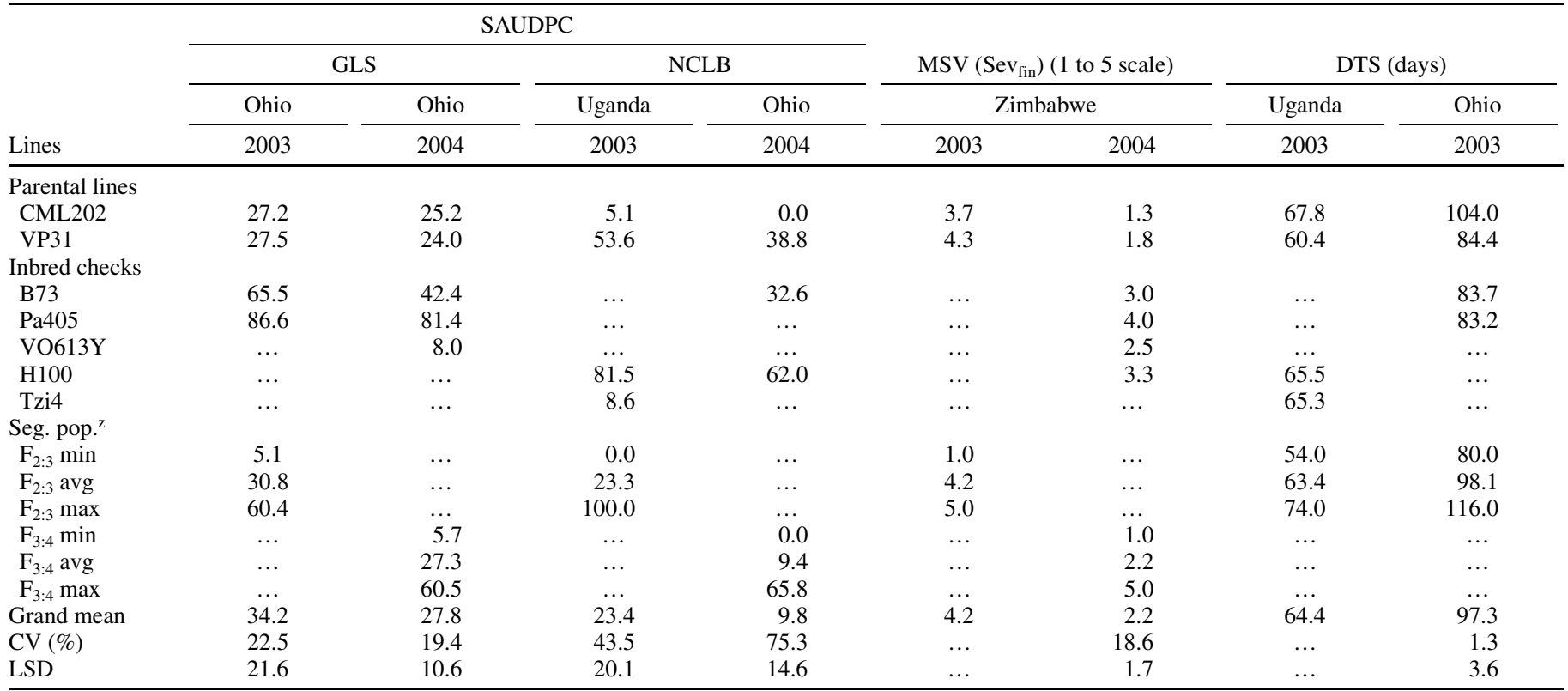

${ }^{\text {y }}$ C. zeae-maydis causes gray leaf spot (GLS), E. turcicum causes northern corn leaf blight (NCLB), and MSV causes maize streak. A standard 1-to-5 scale was used for MSV severity ratings; $\mathrm{Sev}_{\text {fin }}=$ assessed final severity rating for MSV; DTS = days to silking. Data represent experimental mean including the check inbreds.

${ }^{\mathrm{z}}$ Seg. pop. $=$ segregating populations, $\min =$ minimum, avg $=$ average, $\max =$ maximum,$C V=$ coefficient of variation, and LSD $=$ least significant difference 
intermediate and similar, 29-32\% final PLAA in both trials. The differences between the parents and the grand mean of all families were not significantly different $(P>0.05)$. The inbred line VO613Y, from which resistance of VP31 was derived, had a relatively low PLAA score of $13 \%$. The most resistant $\mathrm{F}_{2: 3}$ family had $8 \%$ final PLAA and the most susceptible family had $80 \%$ PLAA. Overall, 156 of the 410 families had final PLAA $<30 \%$ (less than either parent) and 87 families had final severity scores of $>45 \%$ PLAA.

Differences in resistance reaction of CML202 compared with VP31 were noted. Fewer and smaller lesions occurred on VP31 on the entire plant whereas, on CML202, lesions appeared later in the season, were larger, and blighted leaves mainly below the ear.

NCLB. Weather conditions in 2003 in Uganda favored development of severe NCLB epidemics. As a result, a large portion of the $\mathrm{F}_{2: 3}$ families were extensively blighted ( $>50 \%$ final PLAA). The resistant and susceptible parents differed significantly $(P<$ 0.01 ) for severity of NCLB in both seasons. Parental inbred CML202 expressed a relatively high level of resistance, with only 8\% final PLAA at leaf senescence in the Uganda trial and 0\% final PLAA in Ohio (Table 2). The susceptible parental line, VP31, was severely damaged ( $>60 \%$ final PLAA) in both seasons and locations, with disease scores similar to the most susceptible checks (inbred lines B73 and H100). In Uganda, only three families had $0 \%$ final PLAA whereas 156 of the 410 families had final PLAA $>50 \%$. The distribution of severity ratings did not fit a normal curve (Fig. 2) and transgressive segregation was observed for resistance in the $\mathrm{F}_{2: 3}$ but not the $\mathrm{F}_{3: 4}$.

Maize streak. Evaluations of maize streak severity following artificial inoculation showed infection of all $\mathrm{F}_{2: 3}$ and $\mathrm{F}_{2: 4}$ families and checks. Severity values of families ranged from resistant to susceptible during both seasons (Fig. 3). The CML202 parent previously reported as 2.5 across seasons on a 1-to-5 severity assessment scale (41) had a mean score of 3.7 and VP31 had a mean score of 4.3 in 2003 . The majority of the $F_{2: 3}$ families had disease scores $>2.0$ and 105 displayed a score of 5.0. In 2004, CML202 had a mean score of 1.3 and that of the susceptible inbred checks was 3.2. The $\mathrm{F}_{3: 4}$ mean was 2.2 and the final ratings of 35 families were not significantly different from that of
CML202. Across two seasons, the mean rating was 2.5 for CML202 and 3.1 for VP31.

Genotypic analysis. The majority of the markers used for genotyping segregated 1:2:1 as expected. Single-factor ANOVA showed significant association $(P<0.05)$ between the SSR markers for consensus rQTL regions and disease severity (Table $3)$. In some cases, only one of the two SSR markers was significant (e.g., in bins 2.09, 3.06, and 8.06). Because of this, we also analyzed the association of the entire marker interval with the resistance data.

GLS. Single-factor ANOVA for GLS resistance showed that both markers for the consensus rQTL in bin 4.08 were significantly $(P<0.05)$ associated with resistance at the final rating and

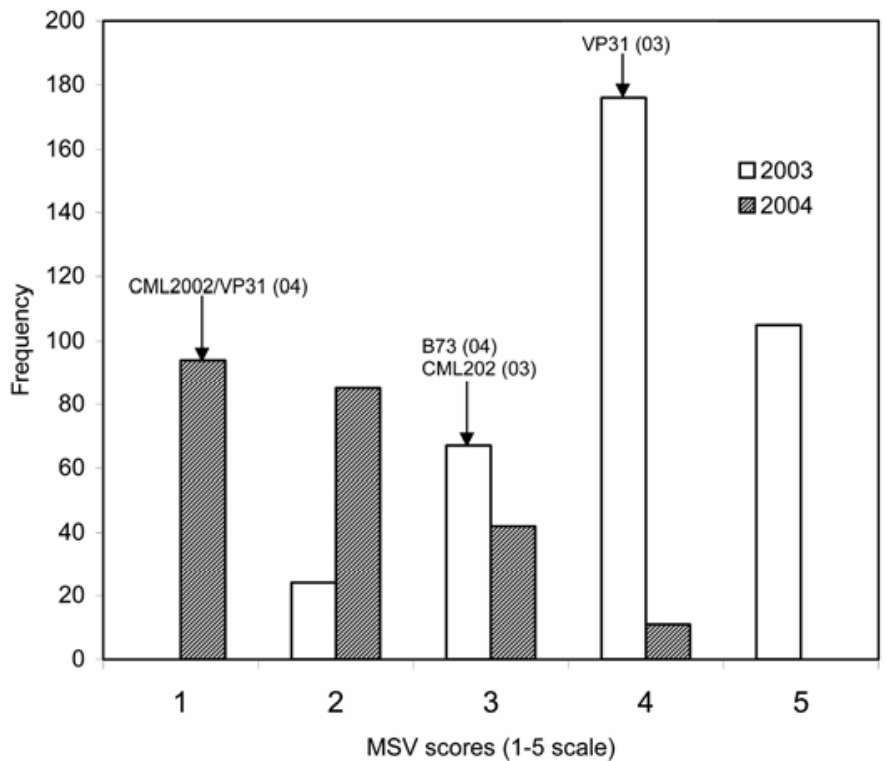

Fig. 3. Frequency distribution of final disease severity rating of $F_{2: 3}$ and $F_{3: 4}$ from CML202/VP31 cross evaluated for maize streak virus at CIMMYT, Zimbabwe (2003 and 2004), respectively.

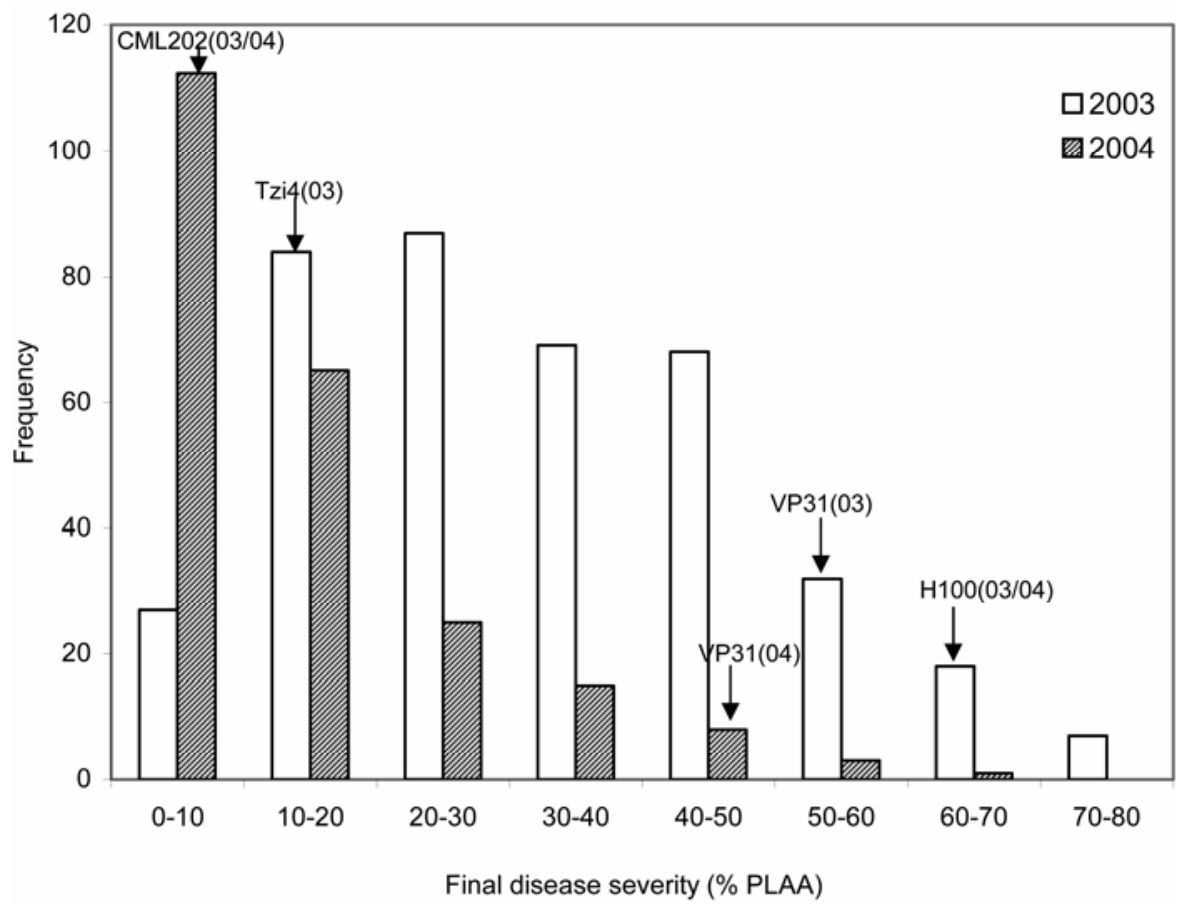

Fig. 2. Frequency distribution of final disease severity ratings (percentage leaf area affected [PLAA]) of $\mathrm{F}_{2: 3}$ and $\mathrm{F}_{2: 4}$ progenies from CML202/VP31 cross evaluated for northern corn leaf blight near Namulonge, Uganda (2003) and Wooster, OH (2004), respectively. 
for SAUDPC. The significance of a GLS candidate rQTL in bin 2.09 was marginal and more variable. The mean severity of genotypic classes for GLS phenotype also showed that families with homozygous alleles at bin 4.08 from the resistant parent were associated with resistance. The locus at bin 2.09 had a contrasting effect on resistance (Table 4 ) and the mean severity ratings were not significantly different among genotypic classes.

NCLB. Markers for rQTL associated with NCLB resistance on chromosomes 3 and 5 were significantly $(P<0.05)$ associated with resistance at final ratings and for SAUDPC, with the exception of umc2169 in bin 3.06 in both generations. Interestingly, both markers at the rQTL position on chromosome 5 (bin 5.04) were highly significant $(P<0.001)$ for resistance (Table 3$)$. Comparison of genotypic classes for the NCLB phenotype showed that families homozygous for the CML202 alleles for both markers in bin 5.04 were significantly more resistant than families homozygous for the VP31 allele. However, resistance from the rQTL position in bin 8.06 was contributed by VP31 (susceptible) (Table 4).

MSV. The candidate rQTL for resistance to MSV ( $m s v 1$; bin 1.04 to 1.05$)$ was confirmed in each test. The rQTL was highly significant $(P<0.001)$ during both trials. Mean severity scores for maize streak indicated that families homozygous for the CML202 allele, as well as those heterozygous, were significantly $(P<0.05)$ associated with resistance.

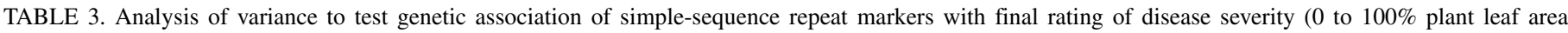

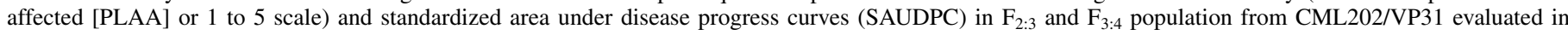
2003 for gray leaf spot (GLS) in Ohio, northern corn leaf blight (NCLB) in Ohio and Uganda, and maize streak (MSV) in Zimbabwe

\begin{tabular}{|c|c|c|c|c|c|c|c|c|}
\hline \multirow[b]{3}{*}{ Marker } & \multirow[b]{3}{*}{ Trait } & \multirow[b]{3}{*}{ Bin } & \multicolumn{4}{|c|}{$P$ of QTL effect $(\mathrm{M} / \mathrm{Gen}(\mathrm{M}))^{\mathrm{x}}$} & & \\
\hline & & & \multicolumn{2}{|c|}{ PLAA $^{\mathrm{y}}$} & \multicolumn{2}{|c|}{ SAUDPC } & \multicolumn{2}{|c|}{$\mathrm{V}_{\mathrm{m}} / \mathrm{V}_{\mathrm{p}}^{\mathrm{z}}$} \\
\hline & & & $\mathrm{F}_{2: 3}$ & $\mathrm{~F}_{3: 4}$ & $\mathrm{~F}_{2: 3}$ & $\mathrm{~F}_{3: 4}$ & $\mathrm{~F}_{2: 3}$ & $\mathrm{~F}_{3: 4}$ \\
\hline umc1551 & GLS & 2.09 & 0.859 & 0.501 & 0.637 & 0.168 & 0.000 & 0.001 \\
\hline umc 2077 & GLS & 2.09 & 0.017 & 0.125 & 0.095 & 0.004 & 0.025 & 0.045 \\
\hline umc1086 & GLS & 4.08 & 0.000 & 0.040 & 0.000 & 0.135 & 0.088 & 0.026 \\
\hline umc1559 & GLS & 4.08 & 0.000 & 0.012 & 0.000 & 0.022 & 0.059 & 0.038 \\
\hline umc1644 & NCLB & 3.06 & 0.033 & 0.022 & 0.055 & 0.019 & 0.013 & 0.029 \\
\hline umc2169 & NCLB & 3.06 & 0.127 & 0.510 & 0.203 & 0.624 & 0.004 & 0.000 \\
\hline phi330507 & NCLB & 5.04 & 0.071 & 0.000 & 0.030 & 0.000 & 0.022 & 0.067 \\
\hline umc1221 & NCLB & 5.04 & 0.165 & 0.000 & 0.048 & 0.000 & 0.015 & 0.079 \\
\hline umc1724 & NCLB & 8.06 & 0.201 & 0.820 & 0.178 & 0.881 & 0.007 & 0.000 \\
\hline mтс0181 & NCLB & 8.06 & 0.036 & 0.692 & 0.015 & 0.824 & 0.025 & 0.000 \\
\hline umc1169 & MSV & 1.04 & 0.016 & 0.000 & $\ldots$ & $\ldots$ & 0.021 & 0.169 \\
\hline bnlg2086 & MSV & 1.04 & 0.005 & 0.000 & $\ldots$ & $\ldots$ & 0.047 & 0.228 \\
\hline
\end{tabular}

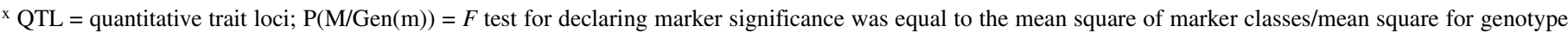
within marker; and SAUDPC $=$ standardized area under disease progress curves.

y PLAA ratings were made only once at the end of the season.

${ }^{\mathrm{z}} \mathrm{V}_{\mathrm{m}} / \mathrm{V}_{\mathrm{p}}$ = phenotypic variation due to marker (marker variance $\left[\mathrm{V}_{\mathrm{m}}\right]$ ) divided by total phenotypic variation (phenotypic variance $\left[\mathrm{V}_{\mathrm{p}}\right]$ ).

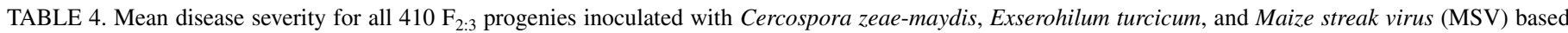
on marker interval analysis for major quantitative trait loci conditioning partial resistance (rQTL) bin positions derived from CML202 and VP31 ${ }^{\mathrm{w}}$

\begin{tabular}{|c|c|c|c|c|}
\hline $\begin{array}{l}\text { Disease, interval } \\
(\text { chromosome bin })^{x}\end{array}$ & Marker interval and map coordinates & Genotypic class ${ }^{\mathrm{y}}$ & Final rating & SAUDPC $^{\mathrm{z}}$ \\
\hline \multicolumn{5}{|l|}{ GLS } \\
\hline \multirow[t]{4}{*}{2.09} & итс1551-итс2077, 591.5-692.4 & $\mathrm{CC}$ & $34.8 \mathrm{~A}$ & $29.9 \mathrm{~A}$ \\
\hline & & $\mathrm{CV}$ & $36.7 \mathrm{~A}$ & $30.1 \mathrm{~A}$ \\
\hline & & VV & $35.8 \mathrm{~A}$ & $30.9 \mathrm{~A}$ \\
\hline & & RR & $36.4 \mathrm{~A}$ & $31.4 \mathrm{~A}$ \\
\hline \multirow[t]{4}{*}{4.08} & итс1086-итс1559, 515.9-561.5 & $\mathrm{CC}$ & $37.7 \mathrm{~A}$ & $33.2 \mathrm{~A}$ \\
\hline & & $\mathrm{CO}$ & $36.4 \mathrm{~A}$ & $30.4 \mathrm{~A}$ \\
\hline & & VV & $31.7 \mathrm{~B}$ & $26.7 \mathrm{~B}$ \\
\hline & & RR & $37.7 \mathrm{~A}$ & $32.3 \mathrm{~A}$ \\
\hline \multicolumn{5}{|l|}{ NCLB } \\
\hline \multirow{4}{*}{3.06} & итс1644-итс 2169, 473.1-491.4 & $\mathrm{CC}$ & $25.4 \mathrm{~A}$ & $18.9 \mathrm{~A}$ \\
\hline & & $\mathrm{CV}$ & $28.9 \mathrm{~A}$ & $19.9 \mathrm{~A}$ \\
\hline & & VV & $26.1 \mathrm{~A}$ & $19.3 \mathrm{~A}$ \\
\hline & & RR & $27.4 \mathrm{~A}$ & $19.4 \mathrm{~A}$ \\
\hline \multirow[t]{4}{*}{5.04} & phi330507- umc1221, 91.3-368.4 & $\mathrm{CC}$ & $24.8 \mathrm{~A}$ & $18.6 \mathrm{~A}$ \\
\hline & & $\mathrm{CV}$ & $26.7 \mathrm{BA}$ & $19.4 \mathrm{BA}$ \\
\hline & & VV & $29.5 \mathrm{~B}$ & $20.4 \mathrm{~B}$ \\
\hline & & $\mathrm{RR}$ & $28.1 \mathrm{~B}$ & $19.9 \mathrm{BA}$ \\
\hline \multirow[t]{4}{*}{8.06} & ттс0181-итс1724, 432.4-456.2 & $\mathrm{CC}$ & $31.3 \mathrm{~A}$ & $20.8 \mathrm{~A}$ \\
\hline & & $\mathrm{CV}$ & $26.0 \mathrm{~B}$ & $19.0 \mathrm{~B}$ \\
\hline & & VV & $25.9 \mathrm{~B}$ & $19.4 \mathrm{~B}$ \\
\hline & & RR & $26.1 \mathrm{~B}$ & $19.2 \mathrm{~B}$ \\
\hline \multicolumn{5}{|l|}{ MSV } \\
\hline \multirow[t]{4}{*}{1.04} & umc1169- bnlg2086, 337.5-401.2 & $\mathrm{CC}$ & $4.0 \mathrm{~A}$ & $\ldots$ \\
\hline & & $\mathrm{CV}$ & $4.2 \mathrm{~A}$ & $\ldots$ \\
\hline & & VV & $4.4 \mathrm{~B}$ & $\ldots$ \\
\hline & & $\mathrm{RR}$ & $4.2 \mathrm{~A}$ & $\ldots$ \\
\hline
\end{tabular}

${ }^{\mathrm{w}}$ Means followed by the same letter are not significantly different at $P=0.05$.

${ }^{x}$ C. zeae-maydis causes gray leaf spot (GLS), E. turcicum causes northern corn leaf blight (NCLB), and MSV causes maize streak.

y $\mathrm{CC}=$ homozygous for the CML202 allele, $\mathrm{CV}=$ heterozygous, VV = homozygous for VP31 allele, and RR = recombinants.

${ }^{\mathrm{z}} \mathrm{SAUDPC}=$ standardized area under disease progress curves. 
Correlations among traits. Phenotypic correlations between disease severity ratings and days to silking (used as a measure of maturity) were significantly $(P<0.05)$ negatively correlated $(-0.41 \leq r \leq-0.50)$. Thus, earlier-maturing genotypes tended to have higher disease severity than later-maturing genotypes.

\section{DISCUSSION}

Our study benefited from the use of a large population and enhanced disease development due to artificial inoculations. As a result of high levels of disease, highly resistant and susceptible families were readily identified. No plants escaped infection among the susceptible checks. Gordon et al. (15) utilized both final disease severity and AUDPC values for QTL analysis of Cercospora zeae-maydis resistance and discovered the same rQTL using both measures of disease severity. This study also showed that a single severity assessment at or near the height of the epiphytotic will usually be as effective at identifying resistant germplasm as the SAUDPC that requires multiple ratings. However, we did observe that, in a few instances, particularly in the $\mathrm{F}_{2: 3}$, the different assessment methods led to different conclusions. We assume that this is due to the segregation within a family of plants with variable degrees of resistance rather than to different onset of infection times or rates of disease progress, although this has not been tested.

In three cases, candidate rQTL 4.08 (GLS), 5.04 (NCLB), and 1.04 (MSV) would be considered effective target rQTL for MAS using the SSR markers. In three other instances (2.09, 3.06, and 8.06), only one SSR marker would be predicted to be useful for selection. In one case (bin 8.06), the susceptible parent contributed rQTL. Only one rQTL ( $m s v 1$, bin 1.04) appeared to have a large effect $(\approx 20 \%$ of total phenotypic variation) on resistance level in the $\mathrm{F}_{3: 4}$. We noted that, among the three diseases, the frequency distribution for GLS was continuous, indicating that resistance is governed by many rQTL, some likely contributed by each parent.

GLS. Interval analysis clearly validated the rQTL from VP31 in bin 4.08 but the rQTL in bin 2.09 did not show the expected allelic effects for resistance. Markers linked to the rQTL in bin 2.09 were significant in only one of two locations and are known to display recessive inheritance (13). The RFLP marker umc127 was associated with both reduction in lesion number and increased incubation period in resistant sister lines of VP31 (15) but its association with disease severity was less consistent. Our results agree with these earlier findings, suggesting that the rQTL in bin 4.08 is the more reliable target locus for resistance breeding.

CML202 is a good source of resistance to multiple diseases but there have been conflicting reports on the resistance to infection by C. zeae-maydis. CML202 was reported to be highly resistant (35) or moderately resistant (K. Pixley, personal communication) but, in another study, it was reported as susceptible (40). Our data, obtained during high epiphytotic seasons, indicated that CML202 was moderately resistant and displayed resistant host responses to infection distinct from those of VO613Y, another resistance source. If CML202 contributed some level of GLS resistance to the population, it could be a possible explanation for the transgressive segregation for resistance observed during both seasons. Based on these observations, we hypothesize that CML202 possesses unlinked rQTL different from those contributed by VO613Y.

NCLB. The effectiveness of candidate NCLB rQTL in bin 5.04 in conferring partial resistance was validated by the reaction of $\mathrm{F}_{2: 3}$ and $\mathrm{F}_{3: 4}$ in tests conducted in both temperate and tropical environments. This rQTL has been reported to affect both lesion number and incubation period (35) and can be considered an excellent target rQTL for breeding purposes. The rQTL in bin 8.06 was found to only affect incubation period in the same study. Our ratings were made based on PLAA, a trait that is closely related to number of lesions. Although one marker (umc2169) on the rQTL position in bin 3.06 was nonsignificant in both generations, interval analysis indicated that this region was associated with resistance and potentially of value for selection. Schechert et al. (35) indicated that NCLB resistance on chromosome 3 was conferred by two rQTL, 22 centimorgans apart and linked in repulsion. These loci primarily affected lesion number.

MSV. The resistant parent CML202 and none of the $410 \mathrm{~F}_{2: 3}$ or any selected $\mathrm{F}_{3: 4}$, families were completely resistant to maize streak. This suggests that resistance conferred by CML202 provides partial protection against maize streak similar to that conferred by other resistance sources such as Tzi4 (18). Across the two seasons, the mean of VP31 was 3.1, indicating that the inbred line displayed intermediate resistance to MSV. VP31 was derived from a South African inbred line, VO613Y, whose reaction to MSV was previously unknown. These data would suggest that VP31 also contributed resistance to the population, consistent with the observed transgressive segregation for reaction to MSV infection.

In our field trials conducted in Zimbabwe, considerable variation was noted in reaction of this population across the two growing seasons. It was hypothesized that environmental conditions, particularly the prolonged drought experienced in 2003, may have affected the level of disease expression because high temperatures and low rainfall are known to influence the development of MSV (32). Isolate variability may also have been partly responsible for these differences. Experiments conducted by Mawere et al. (22) to investigate the stability of MSV resistance in response to infection by isolates collected across Zimbabwe showed significant effects of isolates and genotype-isolate interaction on maize streak severity. However, these effects were found to be practically unimportant because they did not affect trends in ranking of genotypes with known reactions, suggesting that MSV resistance was stable. In our trials, we also observed that the highly resistant and susceptible families maintained their resistance rankings fairly consistently.

The parents in our study were confirmed sources of resistance to different diseases and could be used for pyramiding rQTL from complementary genotypes as described by Servin et al. (36). The current study provides support for the use of several target rQTL to pyramid quantitative resistance to multiple pathogens using MAS as proposed by Pratt et al. (29). The lack of precise QTL locations resulting from low-resolution mapping studies, and the difficulty in obtaining polymorphic markers in a given chromosomal region, may severely limit the use of candidate rQTL as potential targets for MAS. One can also envision that MAS can be implemented on seedlings without disease challenge, thereby allowing additional time and resource savings.

It is interesting to note that some rQTL characterized as having minor effects are located on the same bin positions for major rQTL for other diseases. For example, Pernet et al. $(26,27)$ detected rQTL with minor effects for MSV in bins 3.06, 5.03, and 8.07. These regions also harbor major NCLB rQTL. Similarly, the rQTL region for NCLB in bin 3.05 occurs in the same region as QTL or genes conferring resistance to Maize mosaic virus ( $m v 1$ ), Sugarcane mosaic virus (Scmv1), Wheat streak mosaic virus (Wsm2), and Maize chlorotic dwarf virus (Mcd1) $(17,47)$. Wisser et al. (45) confirmed that bins 3.04 and 3.05 were associated with rQTL for 6 of the 11 diseases of maize integrated into the same genetic map. Associations between qualitative resistance genes or resistance gene analogs and rQTL also are common (41). Gordon et al. (15) found that two RGA were linked to marker umc127 in bin 4.08, a QTL region for resistance to GLS. Similarly, the QTL for NCLB resistance on chromosome $8 \mathrm{~L}$ occurs in the same region as race-specific genes $H t 2$ (bin 8.05) and Htnl (bin 8.06) (23). These associations may explain low but positive correlations of resistance to different diseases observed in this study. Our results also suggested that early-maturing lines with high levels of 
resistance could be selected in spite of negative correlations between maturity and resistance to the three different pathogens because rankings for resistance were fairly consistent.

\section{ACKNOWLEDGMENTS}

Journal paper no. HCS 06-01, The Ohio State University, Ohio Agricultural Research and Development Center (OSU/OARDC). Salaries and research support provided by state and federal funds appropriated to OSU/OARDC. G. Asea received support from USAID IPM/CRSP grant no. CR-19053-425231. The mention of firm names or trade products does not imply that they are endorsed or recommended by OSU over other firms or similar products not mentioned. We thank M. Casey, S. Mawere, and A. Johnston for providing valuable technical assistance; M. Jones for providing invaluable guidance with lab protocols; K. Pixley for assisting the establishment of this project at CIMMYT, Zimbabwe; and D. Francis, S. St. Martin, and anonymous reviewers for helpful suggestions on earlier drafts of the manuscript.

\section{LITERATURE CITED}

1. Adipala, E., Lipps, P. E., and Madden, L. V. 1993. Occurrence of Exserohilum turcicum on maize in Uganda. Plant Dis. 77:202-205.

2. Asea, G., Lipps, P. E., Pratt, R. C., Gordon, S. G., and Adipala, E. 2005. Development of greenhouse inoculation procedures for evaluation of partial resistance to Cercospora zeae-maydis in maize inbreds. J. Phytopathol. 153:647-653.

3. Balint-Kurti, P., and Johal, G. 2008. Maize disease resistance. Pages 229250 in: Handbook of Maize: Its Biology. S. Hake and J. Bennetzen, eds. Springer, New York.

4. Bigirwa, A. G., Julian, A. M., and Adipala, E. 1993. Characterization of Ugandan isolates of Exserohilum turcicum from maize. Afr. Crop Sci. J. 1:69-72.

5. Bigirwa, G., Pratt, R. C., Adipala, E., and Lipps, P. E. 2001. Assessment of gray leaf spot and stem borer incidence and severity on maize in Uganda. Afr. Crop Sci. Conf. Proc. 4:469-474.

6. Bosque-Perez, N. A. 2000. Eight decades of maize streak virus research. Virus Res. 71:107-121.

7. Bubeck, D. M., Goodman, M. M., Beavis, W. D., and Grant, D. 1993. Quantitative trait loci controlling resistance to gray leaf spot in maize. Crop Sci. 33:838-847.

8. Campbell, C. L., and Madden, L. V. 1990. Introduction to Plant Disease Epidemiology. John Wiley \& Sons, New York.

9. Clements, M. J., Dudley, J. W., and White, D. G. 2000. Quantitative trait loci associated with resistance to gray leaf spot of corn. Phytopathology 90:1018-1025.

10. Coaker, G. L., Meulia, T., Kabelka, E., Jones, A. K., and Francis, D. M. 2002. A QTL controlling stem morphology and vascular development in Lycopersicon esculentum $\times$ Lycopersicon hirsutum (Solanaceae) crosses is located on chromosome 2. Am. J. Bot. 89:1859-1866.

11. Davis, G. L., McMullen, M. D., Baysdorfer, C., Musket, T., Grant, D., Staebell, M., Xu, G., Polacco, M., Koster, L., Melia-Hancock, S., Houchins, K., Chao, S., and Coe, E. H. 1999. A maize map standard with sequence core markers, grass genome reference points and 932 expressed sequenced tagged sites (ESTs) in a 1736-locus map. Genetics 152:1137-1172.

12. Federer, W. T., Reynolds, M., and Crossa, J. 2001. Combining results from augmented designs over sites. Agron. J. 93:389-395.

13. Freymark, P. J., Lee M., Martinson, C. A., and Woodman, W. L. 1994. Molecular-marker-facilitated investigation of host-plant response to Exserohilum turcicum in maize (Zea mays L.): components of resistance. Theor. Appl. Genet. 88:305-313.

14. Freymark, P. J., Lee, M., Woodman, W. L., and Martinson, C. A. 1993. Quantitative and qualitative trait loci affecting host-plant response to Exserohilum turcicum in maize (Zea mays L.) Theor. Appl. Genet. 87:537-544.

15. Gordon, S. G., Bartsch, M., Matthies, I., Lipps, P. E., Gevers, H. O., and Pratt, R. C. 2004. Linkage of molecular markers to Cercospora zeaemaydis in maize. Crop Sci. 44:628-636.

16. Hakiza, J. J., Lipps, P. E., St. Martin, S., and Pratt, R. C. 2004. Heritability and number of genes controlling partial resistance to Exserohilum turcicum in maize inbred H99. Maydica 49:173-182.

17. Jones, M. W., Redinbaugh, M. G., Anderson, R. J., and Louie, R. 2004. Identification of quantitative trait loci controlling resistance to maize chlorotic dwarf virus. Theor. Appl. Genet. 110:48-57.

18. Kyetere, D. T., Ming, R., McMullen, M. D, Pratt, R. C., Brewbaker, J., and Musket, T. 1999. Genetic analysis of tolerance to maize streak virus in maize. Genome 42:20-26.
19. Lehmensiek, A., Esterhuizen, A.-M., van-Staden, D., Nelson, S. W., and Retief, A.-E. 2001. Genetic mapping of gray leaf spot (GLS) resistance genes in maize. Theor. Appl. Genet. 103:797-803.

20. Leonard, K. J. 1993. Durable resistance in pathosystems: Maize-northern and southern leaf blights. Pages 99-114 in: Durability of Disease Resistance. T. Jacobs and J. E. Parlevliet, eds. Kluwer Academic, Dordrecht, The Netherlands.

21. Lipps, P. E., Pratt, R. C., and Hakiza, J. J. 1997. Interaction of $H t$ and partial resistance to Exserohilum turcicum in maize. Plant Dis. 81:277-282.

22. Mawere, S., Vincent, V., De Meyer, J., and Pixley, K. V. 2005. Response of four inbred maize lines to inoculation with 20 isolates of Maize streak virus from Zimbabwe. Plant Dis. 90:1485-1490.

23. McMullen, M. D., and Simcox, K. D. 1995. Genomic organization of disease and insect resistance in maize. Mol. Plant-Microbe Interact. 8:811-815.

24. Okori, P., Asea, G., Bigirwa, G., and Adipala, E. 1999. An overview of status of maize diseases in Uganda. Afr. Crop Sci. Conf. Proc. 4:461-466.

25. Parlevliet, J. E. 2002. Durability of resistance against fungal, bacterial and viral pathogens; present situation. Euphytica 124:147-156.

26. Pernet, A. D., Hoisington, J., Dintinger, D., Jewel, C., Jiang, C., Khairallah, M., Letourmy, P., Marchand, J. L., Glaszmann, J. C., and Gonzalez de Leon, D. 1999. Genetic mapping of maize streak virus resistance from the Mascarene source II. Resistance in line CIRAD390 and stability against across germplasm. Theor. Appl. Genet. 99:540-553.

27. Pernet, A. D., Hoisington, J., Franco, M., Isnard, M., Jewel, C., Jiang C., Marchand, J. L., Reynaud, B., Glaszmann, J. C., and Gonzalez de Leon, D. 1999. Genetic mapping of maize streak virus resistance from the Mascarene source I. Resistance in line D211 and stability against different virus clones. Theor. Appl. Genet. 99:524-539.

28. Pratt, R. C., and Gordon, S. G. 2006. Breeding for resistance to maize foliar pathogens. Plant Breed. Rev. 26:119-173.

29. Pratt, R., Gordon, S., Lipps, P., Asea, G., Bigirwa, G., and Pixley, K. 2003. Use of IPM in the control of multiple diseases in maize: strategies for selection of host resistance. Afr. Crop Sci. J. 11:189-198.

30. Raymundo, A. D., and Hooker, A. L. 1981. Measuring the relationship between northern corn leaf blight and yield losses. Plant Dis. 65:325-327.

31. Ritchie, S. W., Hanway, J. J., and Benson, G. O. 1989. How a corn plant develops. Iowa State Univ. Spec. Rep. No. 48.

32. Rose, D. J. W. 1978. Epidemiology of maize streak disease. Annu. Rev. Entomol. 23:259:282.

33. Saghai-Maroof, M. A., Yue, Y. G., Xiang, Z. X., Stromberg, E. L., and Rufener, G. K. 1996. Identification of quantitative trait loci controlling resistance to gray leaf spot. Theor. Appl. Genet. 93:539-546.

34. SAS Institute Inc. 2003. SAS/STAT User's Guide, Version 9.1. SAS Institute Inc., Cary, NC.

35. Schechert, A. W., Welz, H. G., and Geiger, H. H. 1999. QTL for Resistance to Setosphaeria turcica in tropical African maize. Crop Sci. 39:514-523.

36. Servin, B., Martin, O.C., Mezard, M., and Hospital, F. 2004. Toward a theory of marker-assisted gene pyramiding. Genetics 168:513-523.

37. Tuite, J. F. 1969. Plant Pathological Methods: Fungi and Bacteria. Burgess Publishing, Minneapolis, MN.

38. Ward, J. M. J., Laing, M. D., and Rijkenberg, F. H. 1997. Frequency and timing of fungicide applications for the control of gray leaf spot in maize. Plant Dis. 81:41-47.

39. Ward, J. M. J., Stromberg, E. L., Nowell, D. C., and Nutter, F. W. 1999. Gray leaf spot: A disease of global importance in maize production. Plant Dis. 83:884-895.

40. Wegary, D., Habtamu, Z., Singh, H., and Husien, T. 2003. Inheritance of grey leaf spot resistance in selected maize inbred lines. Afr. Plant Prot. 9:53-54.

41. Welz, H. G., and Geiger, H. H. 2000. Genes for resistance to northern corn leaf blight in diverse maize populations. Plant Breed. 119:1-14.

42. Welz, H. G., Schechert, A. W., and Geiger, H. H. 1999. Dynamic gene action at QTLs for resistance to Setosphaeria turcica in maize. Theor. Appl. Genet. 98:1036-1045.

43. Welz, H. G., Schechert, A., Pernet, A., Pixley, K., and Geiger, H. H. 1998. A gene for resistance to the maize streak virus in the African CIMMYT maize inbred line CML 202. Mol. Breed. 4:147-154.

44. Welz, H. G., Xia, X. C., Bassetti, P., and Melchinger, A. E. 1999. QTLs for resistance to Setosphaeria turcica in an early maturing Dent $\times$ Flint maize population. Theor. Appl. Genet. 99:649-655.

45. Wisser, R. J., Balint-Kurti, P. J., and Nelson, R. J. 2006. The genetic architecture of disease resistance in maize: a synthesis of published studies. Phytopathology 96:120-129.

46. Wortmann, C. S., and Eledu, C. A. 1999. Uganda's Agroecological Zones: A Guide for Policy Planners and Policy Makers. Centro Internacional de Agricultura Tropical, Kampala, Uganda.

47. Yuan, L., Duble, C. M., Melchinger, A. E., Utz, H. F., and Lubberstedt, T. 2003. Clustering of QTL conferring SCMV resistance in maize. Maydica 48:55-62. 